\title{
Aplikasi Pembelajaran Sholat Sunnah Berbasis Web Mobile
}

\author{
Muhammad Noor ${ }^{1)}$, Nur Oktaviani ${ }^{2)}$ \\ ${ }^{12)}$ Jurusan Teknik Informatika, Politeknik Negeri Tanah Laut \\ Jl. A Yani Km 6 Pelaihari Tanah Laut Kalimantan Selatan \\ Telp. (0512) 21537, Faks. (0512) 21537 \\ E-mail: muhammadnoorpolitala@gmail.com
}

\begin{abstract}
Abstrak - Aplikasi pembelajaran sholat sunnah merupakan aplikasi yang dibutuhkan dalam pembelajaran sholat. Buku merupakan salah satu media yang digunakan untuk pembelajaran sholat sunnah, namun media seperti buku memiliki beberapa kekurangan seperti fisik yang mudah rusak, dan kurang interaktif yang menyebabkan mudah bosan sehingga diperlukan sebuah aplikasi pembelajaran sholat sunnah yang dapat meningkatkan minat belajar sholat pada masyarakat khususnya anak-anak. Aplikasi ini dibuat berbasiskan web mobile dengan menggunakan bahasa pemrograman PHP dan MySQL sebagai database-nya. Penulis melakukan analisa kebutuhan untuk suatu sistem aplikasi agar dapat dilakukan dengan berbasiskan web mobile. Hasil dari penelitian ini berupa aplikasi pembelajaran sholat sunnah yang berisi materi tentang keutamaan sholat sunnah.
\end{abstract}

Kata Kunci : Pembelajaran Sholat, PHP dan MySQL, Berbasis Web Mobile

\section{PENDAHULUAN}

Perkembangan ilmu pengetahuan dan teknologi sangat pesat terutama dibidang teknologi, salah satu hasil perkembangan teknologi dan komunikasi adalah smartphone. Smartphone merupakan telepon genggam yang memiliki fasilitas lebih selain fasilitas dasar telepon dan mengirim pesan, yaitu kemampuan koneksi internet atau menjalankan suatu aplikasi tertentu. Penggunaan smartphone sebagai sarana pembelajaran merupakan salah satu fungsi smartphone setelah penggunaan sebagai sarana komunikasi dan jejaring sosial.

Setiap muslim memiliki kewajiban untuk melaksanakan ibadah sholat, yaitu sholat 5 waktu dalam sehari semalam dan sholat sunnah.Sejak kecil kita harus menanamkan kebiasaan sholat. Panduan sholat yang ada sekarang hanya terbatas pada media tertulis seperti buku sehingga menimbulkan kesan jenuh pada anak, penulis tertarik untuk membuat suatu media pembelajaran berbasis web mobile yang dapat dijalankan melalui perangkat keras bergerak berupa smartphone. Penggunaan aplikasi pembelajaran sholat dengan menggunakan web mobile ini dapat mempermudah penyampaian informasi dalam mempelajari tata cara gerakan sholat serta menghafal doanya. Dengan penyajian yang sederhana, aplikasi ini diharapkan dapat menarik minat anak dalam mempelajari gerakan sholat beserta menghafal doanya sambil belajar. Aplikasi ini juga memberi kemudahan bagi orang tua dalam membimbing anak dalam mengajarkan tata cara sholat kepada anak. Media pembelajaran untuk anak sangat membantu keefektifan proses pembelajaran dan proses penyampaian pesan pembelajaran. Media pembelajaran sendiri menjadi bagian yang sangat penting dari proses belajar, oleh karena itu, perlu dicari suatu media pembelajaran yang bagus bagi anak, salah satunya media pembelajaran interaktif yang mempunyai beberapa unsur-unsur seperti video, suara, gambar, dan teks sehingga lebih menarik perhatian anak dan anak merasa senang dalam belajar, dibandingkan dengan cara yang masih sangat konvensional. Di dalam aplikasi ini terdapat materi yang bisa digunakan untuk membantu mempermudah pelajaran gerakan sholat, membaca, mendengarkan, memahami serta menghafal doa-doa dalam sholat tersebut. Sistem aplikasi ini hampir sama dengan aplikasi edukasi lainya, akan tetapi aplikasi ini mudah digunakan oleh anak-anak.

Berdasarkan uraian serta permasalahan di atas, untuk mempermudah pembelajaran sholat terhadap anak-anak maka penulis diputuskan untuk membangun sebuah aplikasi, yang berjudul "Aplikasi Pembelajaran Sholat Sunnah Berbasis WebMobile".

\section{TINJAUAN TEORITIS}

\subsection{Aplikasi Mobile}

Mobile dapat diartikan sebagai perpindahan yang mudah dari satu tempat ke tempat yang lain, misalnya telepon mobile berarti bahwa terminal telepon yang dapat berpindah dengan mudah dari satu tempat ke tempat lain tanpa terjadi pemutusan atau terputusnya komunikasi. Aplikasi mobile merupakan aplikasi yang dapat digunakan. Walaupun pengguna berpindah dengan mudah dari satu tempat ketempat lain lain tanpa terjadi pemutusan atau terputusnya komunikasi. Aplikasi ini dapat diakses melalui perangkat nirkabel seperti pager, telepon seluler dan PDA (Romdoni, 2010) karakteristik perangkat mobile: 
1. Ukuran yang kecil, perangkat mobile memiliki ukuran yang kecil. Konsumen menginginkan perangkat yang terkecil untuk kenyamanan dan mobilitas mereka.

2. Memory yang terbatas, perangkat mobile juga memiliki memory yang kecil, yaitu primary (RAM) dan secondary (disk).

3. Daya proses yang terbatas, sistem mobile tidaklah setangguh rekan mereka yaitu desktop.

4. Mengkonsumsi daya yang rendah, perangkat mobile menghabiskan sedikit daya dibandingkan dengan mesin desktop.

5. Kuat dan dapat diandalkan, karena perangkat mobile selalu dibawa kemana saja, mereka harus cukup kuat untuk menghadapi benturan-benturan gerakan, dan sesekali tetesan-tetesan air.

6. Konektivitas yang terbatas, perangkat mobile memiliki bandwith rendah, beberapa dari mereka bahkan tidak tersambung.

7. Masa hidup yang pendek, perangkat-perangkat konsumen ini menyala dalam hitungan detik dan kebanyakan dari mereka selalu menyala.

\subsection{Pembelajaran}

Pembelajaran (learning) adalah suatu proses yang dilakukan peserta didik untuk mencapai sasaran belajarnya. Agar peserta didik dapat mencapai sasaran belajar secara optimal, maka perlu menambah waktu belajar di luar kelas untuk membaca, menulis, diskusi dengan peserta didik lain, menyelesaikan soal-soal dan lain-lain (Setiawati, 2012).

\subsubsection{Media Pembelajaran}

Proses komunikasi dan media merupakan apa saja yang mengantarkan atau membawa informasi ke penerima informasi. Proses belajar mengajar pada hakikatnya merupakan proses komunikasi, informasi atau pesan yang dikomunikasikan adalah isi atau bahan ajar yang telah ditetapkan dalam kurikulum, sumber informasi adalah guru, penulis buku, perancang dan pembuat media pembelajaran lainnya. Sedangkan penerimaan informasi adalah siswa atau warga belajar. Pengertian media pembelajaran bervariasi. Ada ahli media yang membuat definisi media pembelajaran yang mengacu hanya pada alat atau perangkat keras, ada juga yang menonjolkan perangkat lunak (Suherman, 2009)

Media pembelajaran secara umum adalah alat bantu proses belajar mengajar. Segala sesuatu yang dapat dipergunakan untuk merangsang pikiran, perasaan, perhatian dan kemampuan atau keterampilan pembelajar sehingga dapat mendorong terjadinya proses belajar. Batasan ini cukup luas dan mendalam mencakup pengertian sumber, lingkungan, manusia dan metode yang dimanfaatkan untuk tujuan pembelajaran/pelatihan (Harianto, 2012)

Berdasarkan pendapat Suherman dan Harianto dapat disimpulkan bahwa media pembelajaran adalah sarana atau alat yang membantu proses pembelajaran dalam bentuk media cetak dan media elektronik.

\subsection{Sholat Sunnah}

Sholat sunnah adalah semua sholat yang dikerjakan di luar sholat yang fardhu. Sholat sunnah disebut shalat nawaafli atau sholat naafilah. Rasulullah saw. selalu mengerjakan shalat sunnah baik di siang hari maupun di malam hari. Semua sholat sunnah yang dikerjakan itu adalah untuk mendekatkan diri kepada Allah dan mengharapkan tambahan pahala yang lebih banyak. Sholat juga untuk menambah ketaqwaan kepada Allah SWT (Rifa'i, 1993). Sholat sunnah terbagi menjadi 3 kategori yaitu.

1. Sholat Sunnah Temporer (Muaqotatan) terbagi menjadi Sholat Dhuha, Sholat Teraweh, Sholat Witir, Sholat 2 hari raya (Idul Fitri dan Idul Adha), serta Sholat Tahajjud

2. Sholat Sunnah karena ada sebab (Dzatusabab) terbagi menjadi Sholat Gerhana Matahari, Sholat Gerhana Bulan, Sholat Istisqo, Sholat Rawatib, Sholat Ihram, Sholat Tawaf, Sholat Tahiyatul Masjid, Sholat Wudhu, dan Sholat Istikharoh.

3. Sholat Sunnah Mutlak adalah sholat-sholat sunnah yang tidak dikhususkan dengan waktu dan sebab.

\section{KERANGKA PENELITIAN}

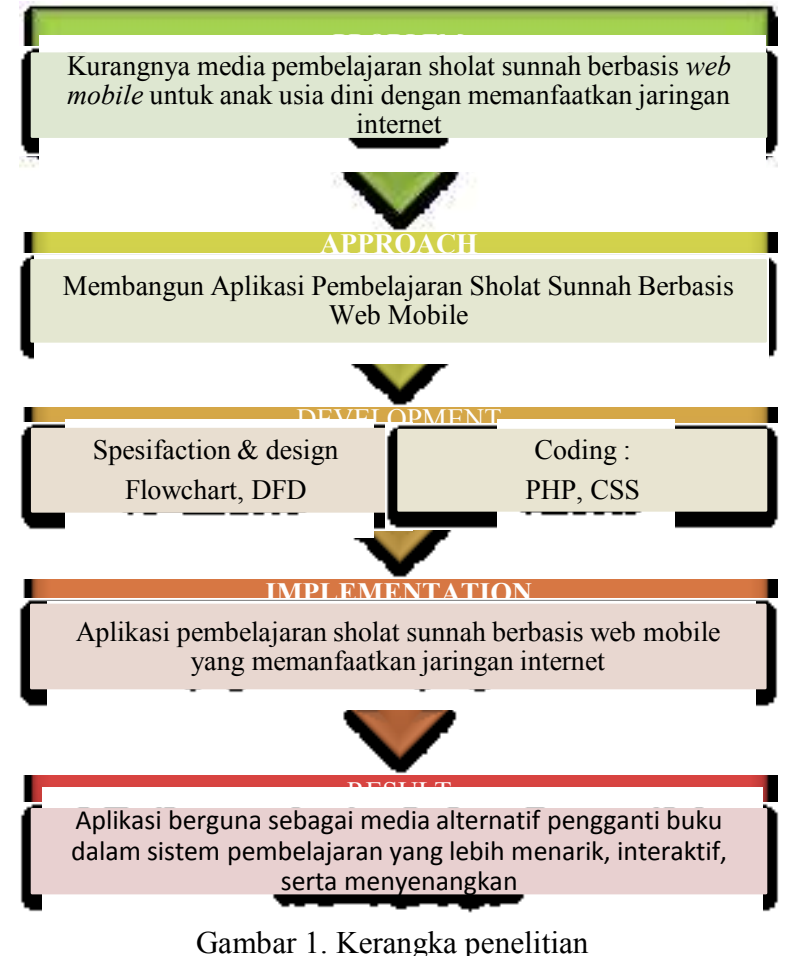


Tabel 1. Keterangan Gambar 1

\begin{tabular}{|c|c|c|}
\hline No & Kerangka & Keterangan \\
\hline 1 & $\begin{array}{l}\text { Problem } \\
\text { (Masalah) }\end{array}$ & $\begin{array}{l}\text { Merupakan masalah yang diperoleh } \\
\text { sebagai alasan pembuatan aplikasi } \\
\text { ini belum adanya media } \\
\text { pembelajaran sholat sunnah untuk } \\
\text { anak usia dini dengan } \\
\text { memanfaatkan android milik orang } \\
\text { tua anak-anak usia dini. }\end{array}$ \\
\hline 2 & $\begin{array}{c}\text { Approach } \\
\text { (Pendekatan) }\end{array}$ & $\begin{array}{l}\text { Merupakan saran yang akan dibuat } \\
\text { sebagai solusi terhadap masalah } \\
\text { yang ada, saran untuk mencapai } \\
\text { tujuan atau hasil yang diinginkan, } \\
\text { dengan membangun aplikasi } \\
\text { pembelajaran sholat sunnah } \\
\text { menggunakan android. }\end{array}$ \\
\hline 3 & $\begin{array}{l}\text { Development } \\
\text { (Pengembang) }\end{array}$ & $\begin{array}{l}\text { Merupakan tahap pengembang } \\
\text { pembuatan aplikasi yang berisi } \\
\text { spesifikasi, desain, flowchart, DFD } \\
\text { dan menggunakan bahasa PHP dan } \\
\text { CSS }\end{array}$ \\
\hline 4 & $\begin{array}{l}\text { Implementation } \\
\text { (Implementasi) }\end{array}$ & $\begin{array}{l}\text { Merupakan studi kasus yang } \\
\text { disarankan } \\
\text { pengimplementasian } \\
\text { pembelajaran sholat aplikasi } \\
\text { menggunakan android sunnah } \\
\text { memanfaatkan jaringan internet }\end{array}$ \\
\hline 5 & Result (Hasil) & $\begin{array}{l}\text { Merupakan suatu solusi terhadap } \\
\text { masalah yang ada, dimana dengan } \\
\text { aplikasi pembelajaran sholat sunnah } \\
\text { menggunakan android ini nantinya } \\
\text { diharapkan berguna sebagai media } \\
\text { alternative penganti buku dalam } \\
\text { sistem pembelajaran sholat sunnah } \\
\text { yang lebih menarik, interaktif, serta } \\
\text { menyenangkan. }\end{array}$ \\
\hline
\end{tabular}

\section{DESAIN DAN IMPLEMENTASI SISTEM}

\subsection{Perancangan Sistem}

\subsubsection{Entity Relationship Diagram}

Entity Relationship Diagram menggambarkan data dan hubungan antar data secara global dengan menggunakan Entity Relationship Diagram. Gambaran Entity Relationship Diagram pada Aplikasi Pembelajaran Sholat Sunnah, dapat dilihat pada Gambar 2.

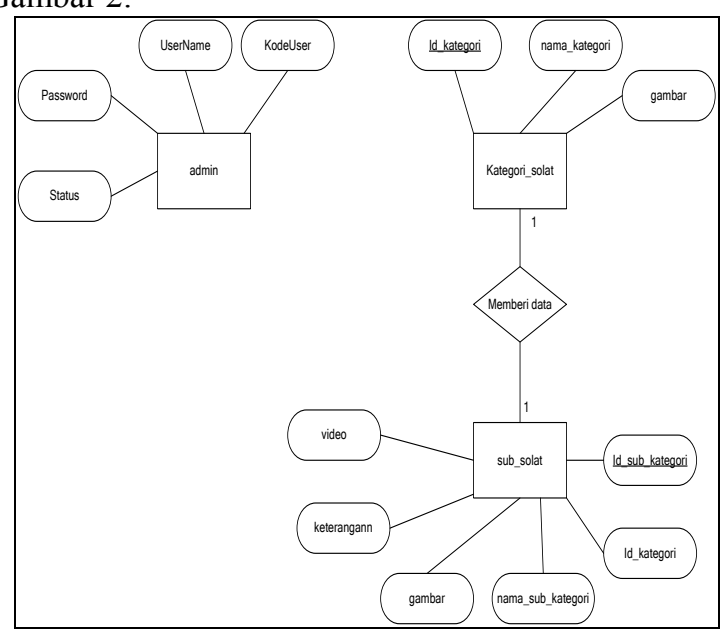

Gambar 2. Entity Relationship Diagram

Gambar 2 merupakan Entity Relationship Diagram yang menggambarkan hubungan antar data kategori dan sub kategori.Kategori solat merupakan entitas dan memiliki atribut seperti id kategori, nama kategori dan gambar dimana id kategori sebagai primary key. Sub solat merupakan entitas dan memiliki atribut seperti id sub kategori, id kategori, nama sub kategori, gambar, keterangan dan video dimana id sub kategori sebagai primary key.

\subsubsection{Diagram Konteks}

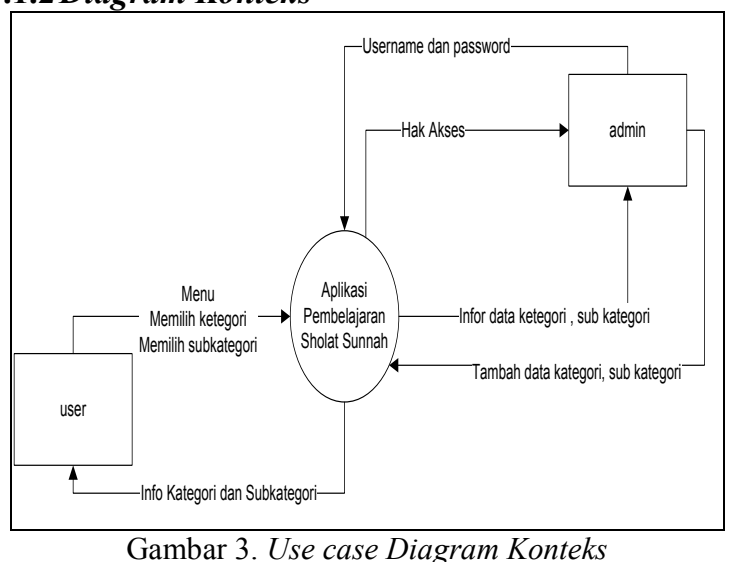

Gambar 3 merupakan diagram konteks mendeskripsikan tentang keseluruhan sistem atau gambaran umum sistem yang akan dibuat. Diagram konteks ini berisi "siapa saja yang memberi data dan data apa saja ke sistem, serta kepada siapa saja informasi dan informasi apa saja yang harus dihasilkan sistem".

\subsubsection{Diagram Dekomposisi}

Diagram dekomposisi atau hierarchy chart menunjukan dekomposisi atas bawah dan struktur sebuah sistem. Aliran data yang ada pada sistem digambarkan dengan lebih rinci dapat dilihat pada Gambar 4 berikut.

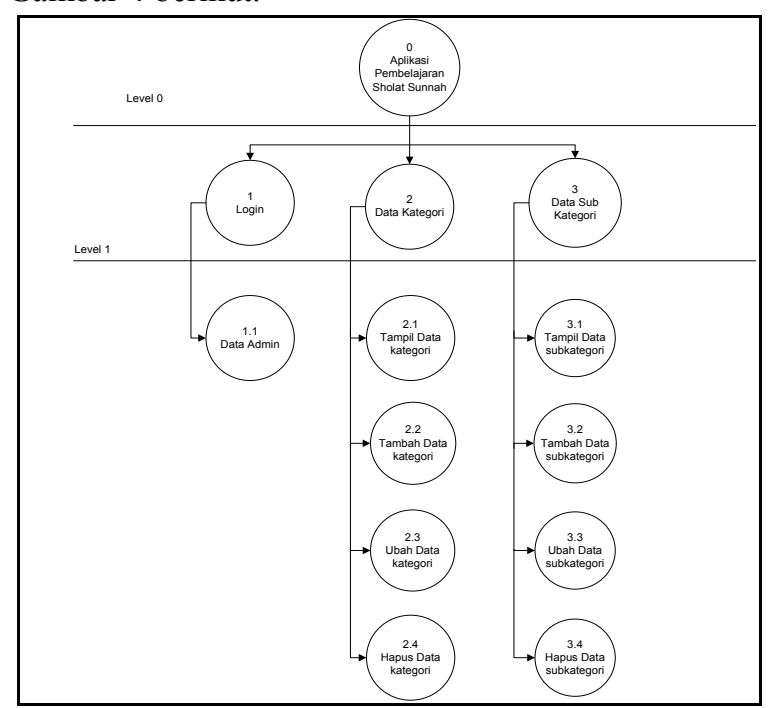

Gambar 4. Diagram dekomposisi 
Diagram dekomposisi yang mempunyai level 0 yang berisi login, data Kategori dan data sub kategori. Level 1 merupakan isi dari data kategori dan sub kategori. Masing-masing data berisi beberapa proses seperti tampil, tambah, cari, ubah, dan hapus.

\subsection{Rancangan Logika}

\subsubsection{Flowchart menu utama}

Flowchart menu user merupakan alur flowchart yang menjelaskan jalannya suatu aplikasi dimulai dari yang terdiri dari kategori, sub kategori, dan detail. Detail alur flowchart dapat dilihat pada Gambar 5.

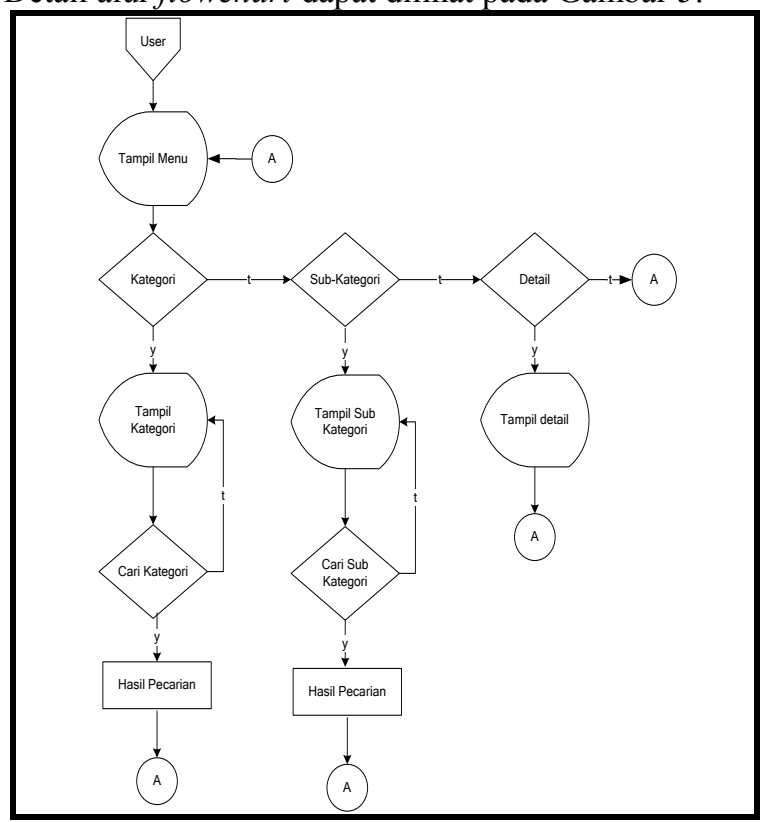

Gambar 5. Flowchart Menu User

\subsection{Perancangan Antarmuka (Interface)}

Perancangan antarmuka (interface) merupakan rancangan sebuah aplikasi yang nantinya akan di buat.

\section{Form login masuk pada sistem}

Menu login berfungsi untuk memberikan hak akses kepada pengguna agar dapat menggunakan Aplikasi Pembelajaran Sholat Sunnah yang dibangun. Admin memasukan nama pengguna dan password. Setelah admin memasukan nama pengguna dan password yang benar maka, admin akan dibawa ke menu home aplikasi. Form login dapat dilihat pada Gambar 6.

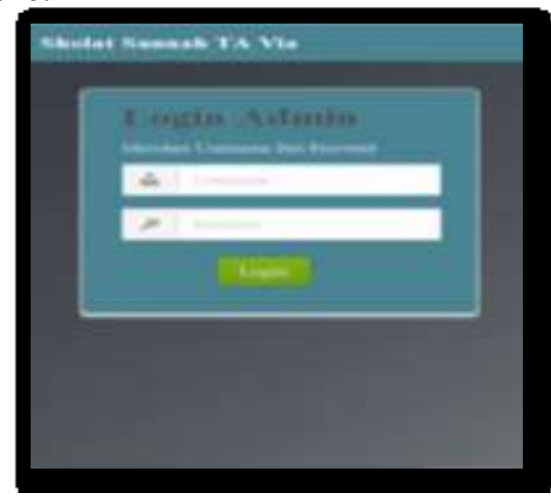

Gambar 6 Form Login

\section{Form Halaman Administrator}

Form halaman administrator adalah halaman utama dari Aplikasi Pembelajaran Sholat Sunnah setelah melakukan login. Form home dapat dilihat pada Gambar 7.

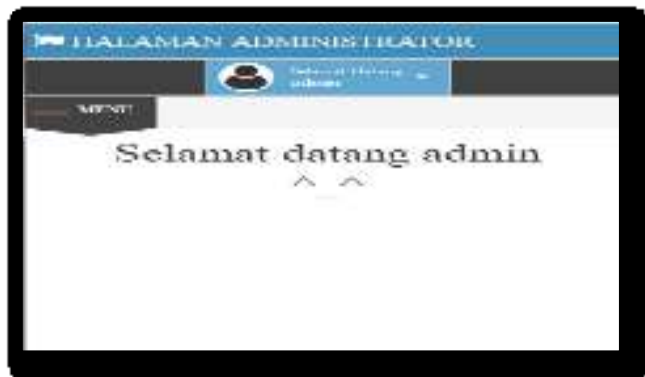

Gambar 7. Form Halaman Admin

\section{Form Menu Data Kategori}

Form menu data kategori adalah form yang didalamnya berisi tabel data kategori dan dengan beberapa fungsi button yaitu simpan, ubah, dan menghapus. Form menu data kategori dapat dilihat pada Gambar 8 .

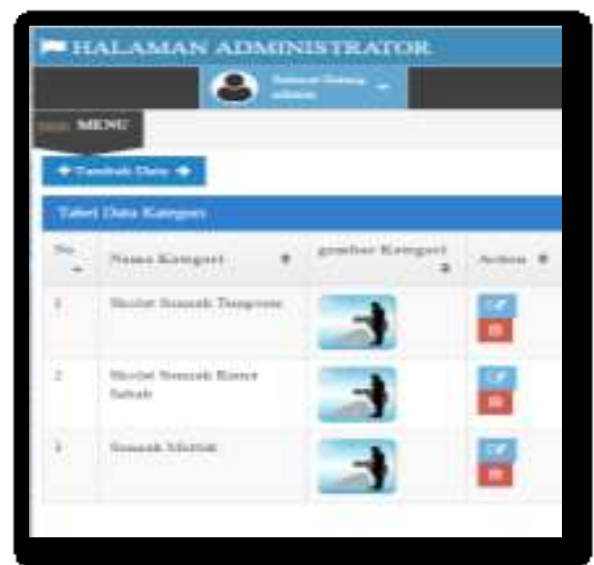

Gambar 8. Form Menu Data Kategori

\section{Form Menu data Sub Kategori}

Form menu data sub kategori adalah form yang didalamnya berisi tabel data sub kategori dengan beberapa fungsi button yaitu simpan, ubah, hapus. Form menu data sub kategori jaga dapat dilihat pada Gambar 9.

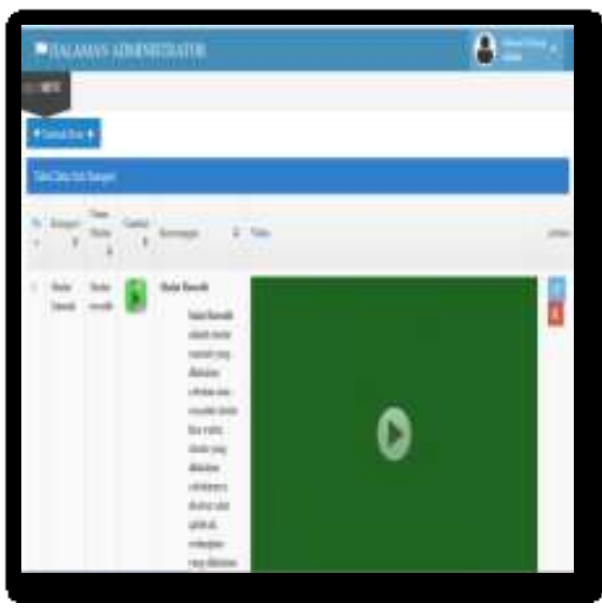

Gambar 9. Form Menu Data sub Kategori 


\section{Form Menu Utama}

Form Rancangan Menu utama merupakan halaman yang pertama kali akan ditampilkan ketika sistem dijalankan di android. Rancangan halaman utama dapat dilihat pada Gambar 10.

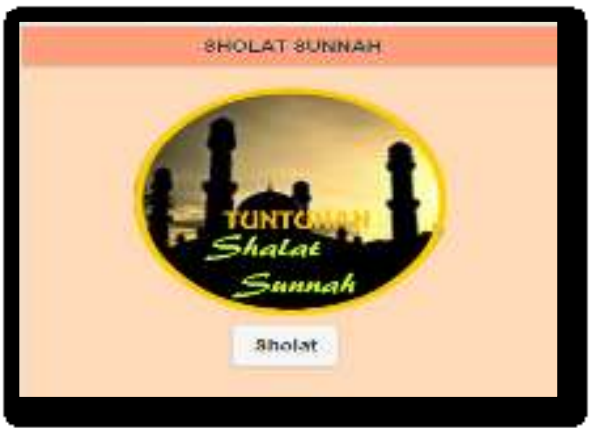

Gambar 10. Rancangan Halaman Utama

\section{Form Menu User Bagian Kategori}

Form menu user bagian kategori adalah form yang didalamnya berisi button untuk menampilkan sub kategori, button untuk menampilkan info dan button untuk kembali kemenu utama. Form menu user bagian kategori dapat dilihat pada Gambar 11.

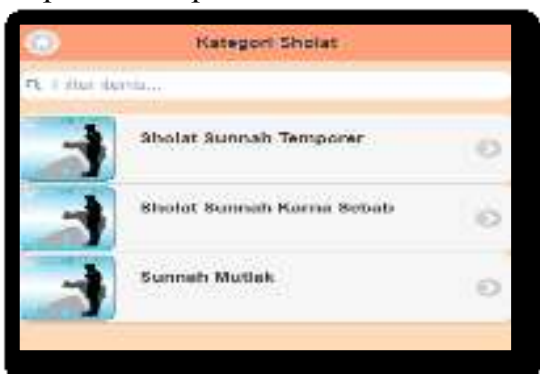

Gambar 11. Form User Bagian Kategori

\section{Form Menu User Bagian Sub Kategori}

Form menu user bagian sub kategori adalah form yang didalamnya berisi button untuk menampilkan detail dan button untuk kembali kemenu kategori. Form menu user bagian kategori dapat dilihat pada Gambar 12

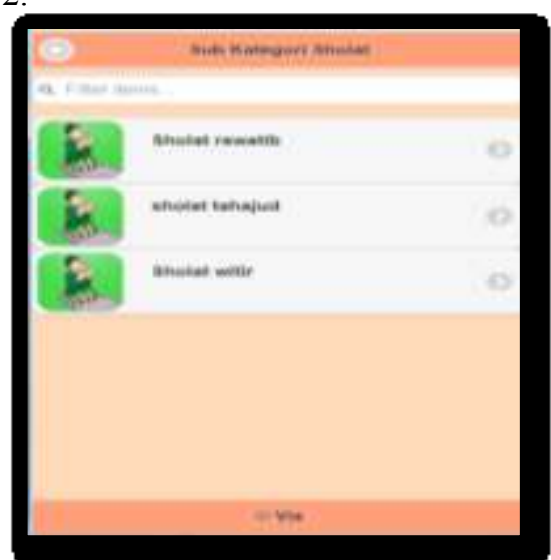

Gambar 12. Form User Bagian sub Katergori

\section{Form Menu User bagian detail}

Menu user bagian detail merupakan halaman berisi keterangan tentang sholat. Rancangan menu user bagian detail dapat dilihat pada gambar 13 berikut:

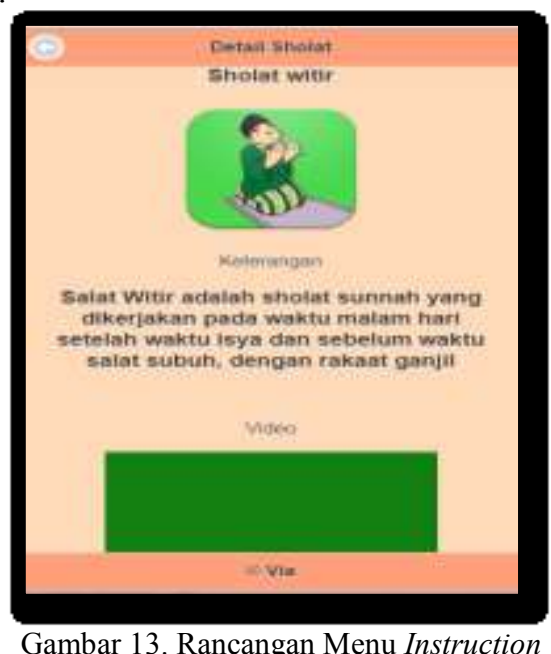

\section{Form Menu User bagian tentang}

Menu user bagian tentang merupakan halaman berisi keterangan tentang. Rancangan menu user bagian tentang dapat dilihat pada Gambar 14.

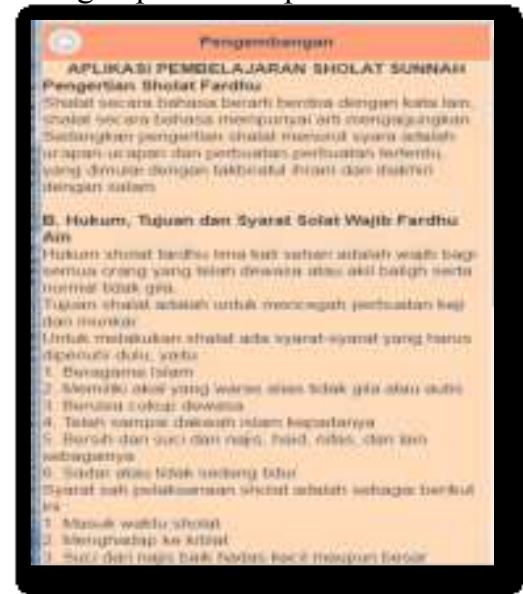

Gambar 14. Rancangan Menu Tentang

\section{PENUTUP}

\subsection{Kesimpulan}

Dari hasil pembahasan tentang Aplikasi pembelajaran sholat sunnah berbasis web mobile yang berjalan pada media yang berbasiskan Mobile dimana berisi penjelasan tentang sholat sunnah. Saat User membuka aplikasi, pertama aplikasi akan menampilkan daftar sholat sunnah dan apabila nama sholat tersebut di pilih maka akan menampilkan judul sholat, rincian tatacara sholat maupun video yang berhubungan dengan sholat sunnah.

Aplikasi pembelajaran sholat sunnah berbasis web mobile yang telah terancang mampu memberikan inovasi baru pada pengembangan aplikasi berbasis web mobile khususnya pada aplikasi pembelajaran sholat sunnah ini yang berisikan penjelasan dan tata cara serta video yang berhubungan dengan sholat yang 
dapat dengan mudah digunakan oleh pemakai dimana saja dengan syarat terkoneksi jaringan internet yang stabil dan cepat.

\subsection{Saran}

Aplikasi yang dibuat ini tidak terlepas dari kekurangan dan kelemahan. Oleh karena itu, untuk kebaikan perkembangan sistem lebih lanjut, maka perlu diperhatikan beberapa hal, diantaranya:

1. Aplikasi ini harus terkoneksi internet yang stabil agar video dapat berjalan dengan lancar

2. Aplikasi ini diperlukan beberapa fitur pendukung seperti permainan edukatif dan kuis dan video tatacara sholatnya

\section{DAFTAR PUSTAKA}

Harianto. "Pentingnya Pendidikan Anak Usia Dini" URL:http://belajarpsikologi.com/pentingnyapendidikan-anak-usia-dini/. Diakses pada tanggal 12 Mei 2016 pukul 21.56 WITA

Rifa'i, Moh. 1993. Kumpulan Salat-Salat, Semarang: CV Toha Putra

Romdoni, A. 2010. Pengertian Aplikasi Mobile. [Online] Dapat diakses di http://agusbarupunyablog.blogspot.com
Setiawati, Novita. 2012. Pengembangan Mobile Learning (M-Learning) Berbasis Moodle Sebagai Daya Dukung Pembelajaran Fisika Di Sma Skripsi. Skripsi, 17.

Suherman, Yuyus. 2009. "Makalah Pengembangan Media Pembelajaran Bagi ABK". Bandung: Disampaikan pada Diklat Profesi Guru PLB Wilayah X Jawa Barat Bumi Makmur, Lembang Bandung.

\section{Biodata Penulis}

Muhammad Noor, M.H.I, lahir di Martapura pada tanggal 01 November 1985. Penulis pertama memperoleh gelar magister di Hukum Islam Akhwal As-Syakhsiyah Universitas Sunan Giri Surabaya Indonesia pada tahun 2012. Saat ini penulis bekerja sebagai Dosen Jurusan Teknik Informatika Politeknik Negeri Tanah Laut.

Nur Oktaviani, lahir di Pelaihari pada tanggal 7 Oktober 1995. Penulis kedua memperoleh gelar A. Md di Jurusan D3 Teknik Informatika Politeknik Negeri Tanah Laut pada tahun 2016. 